\title{
Genetic variability and phenotypic plasticity in pupal colour and its adaptive significance in the swallowtail butterfly Papilio polyxenes
}

\author{
Wade Hazel, \\ Ruth Brandt and \\ Todd Grantham
}

Department of Biological Sciences, DePauw

University, Greencastle, IN 46135, U.S.A.

\begin{abstract}
Genetic variability and phenotypic plasticity have been suggested as mutually exclusive ways by which adaptation to environmental heterogeneity can be accomplished. The genetic and environmental components of variation in the darkness of brown pupae of the swallowtail butterfly Papilio polyxenes were investigated. Variation in darkness was found to be both genetic and environmental, with the darkness of the pupation site having a significant influence on the darkness of pupae, thus allowing for the production of cryptic brown pupae in nature. These results suggest that the evolution of phenotypic plasticity in a trait need not be to the exclusion of the maintenance of genetic variation in that trait. The results of field experiments show that cryptic pupae have a higher probability of escaping predation relative to noncryptic pupae.
\end{abstract}

\section{INTRODUCTION}

Phenotypic plasticity is the degree to which the phenotype of an organism is modified by the environment (Bradshaw, 1965; Gause, 1947). Because plasticity often occurs as a predictable response to environmental variation, it is thought to be one way by which adaptation to environmental heterogeneity can be accomplished (Thoday, 1953; Baker, 1965; Bradshaw, 1965; Jain, 1979). Since an alternative means of adaptation to heterogeneous environments would be the production of genetically variable, but phenotypically inflexible, offspring, it has been suggested that phenotypic plasticity and genetic variability should be inversely related (Thoday, 1953; Levins, 1963; Marshall and Jain, 1968; Jain, 1978, 1979), but support for this hypothesis has been equivocal (Wilken, 1977; Gottlieb, 1977; Schlicting and Levin, 1984; Scheiner and Goodnight, 1984). Here, we present the results of experiments investigating the genetic and environmental basis and adaptive significance of phenotypic variation in the darkness of brown pupae of the swallowtail butterfly Papilio polyxenes.
Phenotypic plasticity in pupal colour in Papilio polyxenes

In P. polyxenes and many other species of swallowtail butterflies, pupal colour is a phenotypically plastic trait. In these species, pupae are usually either green or brown, with pupal colour to a large extent dependent on environmental cues associated with the colour of the pupation site. As a result, pupae are cryptic on their natural pupation sites (Clarke and Sheppard, 1972; Wiklund, 1972, 1975; West et al., 1972; Smith, 1978; Hazel and West, 1979; West and Hazel, 1979, 1985; Sims, 1983).

The experiments described here concern variation in the colour of Papilio polyxenes brown pupae. When $P$. polyxenes larvae are reared on autumnal photoperiods (e.g., 12L:12D), nearly all pupae produced are brown and enter diapause (West et al., 1972; Hazel and West, 1983). West et al. (1972) observed that these pupae vary considerably in darkness and have suggested that this variation may be correlated with the darkness of their pupation sites allowing for the production of highly cryptic pupae in nature. This might be especially 
important during the overwintering generation, when brown pupae are exposed to predators for 8 to 9 months.

In this report we describe experiments which show that the darkness of brown $P$. polyxenes pupae is correlated with the darkness of their pupation sites. We also show, using full sib analysis of variance, that there is a significant genetic component to variation in darkness. In addition, we report the results of field experiments indicating that cryptic brown pupae have a higher probability of escaping detection by predators relative to noncryptic brown pupae.

\section{MATERIALS AND METHODS}

\section{Rearing}

Larvae were obtained from the eggs of wild $P$. polyxenes females and reared in the lab on short day photoperiods (12L:12D or 11L:13D) so as to enhance the production of brown pupae. Temperature was not strictly controlled and ranged from 24 to $28^{\circ} \mathrm{C}$.

Details of the rearing procedure have been described elsewhere (Hazel, 1977). In general, larvae were reared in round plastic rearing dishes and fed fresh food plant (Daucus carota) daily. Several early instar larvae from a single female parent were maintained in a single dish, but as they grew, the number of larvae per dish was reduced, so that by the time larvae reached the fifth instar each dish housed only a single larva.

\section{Pupation conditions}

When swallowtail larvae enter the prepupal stage, they evacuate the contents of their guts as a conspicuous watery discharge. In nature, after gut evacuation larvae leave their food plant and several hours later settle on a pupation site. In our experiments, we hoped to determine whether the darkness of the pupation site had an influence on the darkness of brown pupae; so larvae were removed from rearing dishes immediately after gut evacuation and placed in either black or white construction paper cylinders $(23 \mathrm{~cm}$ tall, $8 \mathrm{~cm}$ in diameter $)$. Black cylinders were placed upright on black construction paper, while white cylinders were placed upright on white construction paper. Clear plastic dish tops were placed on top to prevent larvae from escaping. The pupation chambers were illuminated continuously from above by fluorescent lights.

\section{Darkness determination}

The darkness of pupae was determined by two methods. The first involved having five people rank pupae according to their relative darkness. Twenty six pupae, 15 formed in the white cylinders and 11 formed in the black cylinders, representing the offspring of four wild caught females, were ranked, with the lowest rank given to the darkest pupa. The rankers did not know in which pupation cylinder an individual pupa was formed. The agreement among rankers was measured by Kendall's Coefficient of Concordance. The rankings of pupae formed in the two types of pupation cylinders were tested against the null hypothesis of there being no difference, by a Mann Whitney U Test.

For a more quantitative measure of the darkness of pupae we measured the reflections of living diapausing brown pupae and the empty pupal cases of eclosed non-diapausing brown pupae using a Bausch and Lomb Colour Analyzer Reflectance Attachment (Cat. No. 33-29-44-01) as an accessory to a Bausch and Lomb Spectronic 20 (Cat. No. 33-31-72). The reflectance attachment allows one to measure the proportion of light of a given wavelength that is reflected by a sample; the remaining light being either absorbed by the sample or transmitted through the sample, depending on how translucent it is. Percent reflectance was determined for ten wavelengths $(415,445,475$, $505,535,565,595,625,655$ and $685 \mathrm{~nm})$. From these data, we calculated the brightness values (darkness) of the pupae and empty cases using the Bausch and Lomb Trichromatic Coefficient Computing Form (Cat. No. 33-29-12-101). Since the reflectance attachment only allows for the measurement of an area of approximately $2 \mathrm{~mm}$ by $8 \mathrm{~mm}$, we did not measure the brightness of entire pupal cases. Instead, we measured the brightness of the middle of the first dorsal abdominal segment of the living pupae and the ventral surface of the head capsules of the empty pupal cases. These areas were chosen because of the ease with which they could be positioned for measurement.

Brightness values were calculated for a total of 142 individuals. Of these, 42 were calculated from the reflectances of living pupae (21 per pupation treatment) representing the offspring of three females, and 100 were calculated from the reflectances of empty pupal cases ( 50 per pupation treatment), representing the offspring of 10 females. 
The brightness values for pupae and empty cases from the two pupation treatments were compared using a t-test.

\section{Genetic analysis}

Genetic variation in the darkness of pupae was estimated by full sib analysis of variance. Two analyses were performed on the brightness values of the 100 pupal cases obtained from the pupae formed in the black and white pupation treatments described above (50 pupae/treatment). The 100 cases represented the offspring of 10 wild females distributed equally between the two pupation treatments ( 5 offspring/female parent/treatment). All 10 wild females were taken from a single wild population, and although they may have mated with more than one male, because of sperm precedence in this species (Clarke and Sheppard, 1962), all offspring were full sibs. Thus, the two ANOVAs partition the variance within the two treatments into among families and within families components.

\section{Field experiments}

To determine whether cryptic brown pupae were less likely to be detected and preyed upon, field experiments were conducted during the fall and winter months of 1982-83, 1983-84 and 1984-85. The experiments involved attaching cryptic and noncryptic brown pupae to trees and fence posts and monitoring their survival throughout the winter. Pupae were attached approximately $30 \mathrm{~cm}$ above the ground using either contact cement (1982-83, 1983-84) or clear silicon sealant (198485). The height and positioning of the pupae closely mimicked those of $P$. polyxenes pupae on natural pupation sites (West and Hazel, 1979). Whether a given pupation site had a cryptic or noncryptic, or light or dark noncryptic pupa, was determined by the toss of a die; as was whether the pupa faced north, south, east or west. When this procedure called for the attachment of a cryptic pupa to a given pupation site, we attempted to match the darkness of the pupa to the darkness of its site. Likewise, when the attachment of noncryptic pupae was required, we used pupae that, in our judgment, failed to match the darkness of their pupation sites.

For the 1982-83 experiment (82A), pupae were attached to tree trunks at approximately 10 metre intervals along a linear transect that ran adjacent to an old field. For the 1983-84 experiment (83A) and the 1984-85 experiments ( $84 \mathrm{~A}-\mathrm{D})$, pupae were attached to fence posts at approximately $10 \mathrm{~m}$ intervals (every other post). The fence lines ran adjacent to country roads on one side, and were bounded by fields in various stages of use on the other side. For the 1983-84 experiment, pupae were placed along a single linear transect. For the 1984-85 experiments, pupae were placed along four different linear transects.

For all experiments the survival of the pupae was monitored throughout the winter, until they disappeared, were attacked and killed, or died. The survival of the cryptic and noncryptic pupae over approximately the first 2 weeks in the field was compared by chi square analysis. Rates of elimination (daily probabilities of survival) of cryptic and noncryptic pupae over approximately the first 7 weeks in the field were compared using a constant mortality model (West and Hazel, 1982). Dead pupae were eliminated from the analyses and pupae that disappeared were assumed to have been preyed upon, and were therefore included.

\section{RESULTS}

Table 1 shows the average darkness ranks of pupae formed in black and in white pupation cylinders. The five rankers were in almost complete agreement on their assessments of the relative darkness of the pupae (Coefficient of Concordance $=0.95$ ), and pupae formed in the black cylinders were ranked as significantly darker than pupae formed in the white cylinders (Mann Whitney $U=282 \cdot 5$, $p<0 \cdot 001)$. Consistent with these results were the reflectance analyses of living pupae and empty cases (table 2), with pupae formed in the white cylinders being significantly brighter (less dark) than those formed in black cylinders. Interestingly, the values of pupae formed in black cylinders were no different from those of empty cases of pupae formed in black cylinders, while the empty cases of pupae formed in white cylinders were less bright than living pupae formed in white cylinders. This difference is probably because pupae formed in the black cylinders and their empty cases were equally opaque, while the empty cases of pupae formed in the white cylinders, being less pigmented, were more translucent than living pupae formed in those cylinders.

The results of the analyses of variance of the brightness values of the empty cases of pupae formed in the black and white cylinders are given in table 3. For the empty cases of pupae formed in the black cylinders the results were significant, with approximately 50 per cent of the variation in 
Table 1 Average darkness rankings of brown pupae formed in black and white pupation cylinders. Pupae with high average ranks were judged to be lighter than those with low average ranks

\begin{tabular}{lll}
\hline Pupa & Average rank & Pupation cylinder \\
\hline $1-3$ & $25 \cdot 8$ & white \\
$1-1$ & $23 \cdot 2$ & white \\
$5-3$ & $23 \cdot 2$ & white \\
$5-7$ & $23 \cdot 2$ & white \\
$1-2$ & $20 \cdot 6$ & white \\
$5-11$ & $20 \cdot 2$ & white \\
$2-1$ & $20 \cdot 0$ & white \\
$3-7$ & $20 \cdot 0$ & white \\
$3-5$ & $18 \cdot 6$ & white \\
$3-6$ & $18 \cdot 2$ & white \\
$5-9$ & $16 \cdot 8$ & white \\
$2-2$ & $16 \cdot 2$ & white \\
$2-3$ & $14 \cdot 0$ & white \\
$5-5$ & $11 \cdot 4$ & white \\
$3-1$ & $11 \cdot 4$ & black \\
$2-4$ & $11 \cdot 0$ & black \\
$5-1$ & $10 \cdot 2$ & white \\
$5-13$ & $8 \cdot 8$ & black \\
$3-3$ & $8 \cdot 2$ & black \\
$5-8$ & $7 \cdot 8$ & black \\
$3-4$ & $5 \cdot 0$ & black \\
$5-14$ & $4 \cdot 8$ & black \\
$5-10$ & $4 \cdot 2$ & black \\
$5-12$ & $4 \cdot 0$ & black \\
$5-6$ & $1 \cdot 6$ & black \\
$5-4$ & $1 \cdot 4$ & black \\
\hline
\end{tabular}

Table 2 Brightness values (mean and standard error) of living pupae and empty pupal cases for pupae formed in black and in white pupation cylinders

\begin{tabular}{llr}
\hline & \multicolumn{2}{c}{$\begin{array}{c}\text { Pupation cylinder } \\
\text { black }\end{array}$} \\
\hline Empty cases & $12.97 \pm 0.46$ & $8.47 \pm 0.25$ \\
Living pupae & $17.52 \pm 0.96$ & $8.97 \pm 0.68$ \\
\hline
\end{tabular}

Table 3 One way ANOVA of brightness values of empty pupal cases from pupae formed in black and white pupation cylinders

\begin{tabular}{lccc}
$\begin{array}{l}\text { A. Pupae formed in white cylinders } \\
\text { Source }\end{array}$ & $\mathrm{df}$ & $\mathrm{MS}$ & $\mathrm{F}$ \\
\hline $\begin{array}{l}\text { Among families } \\
\text { Within families }\end{array}$ & 9 & $\begin{array}{r}13 \cdot 71 \\
9 \cdot 74\end{array}$ & 1.41 \\
$\begin{array}{l}\text { B. Pupae formed in black cylinders } \\
\text { Source }\end{array}$ & & \\
\hline $\begin{array}{l}\text { Among families } \\
\text { Within families }\end{array}$ & 9 & $10 \cdot 21$ & $6 \cdot 18^{*}$ \\
$*=p<0.001$. & 1.65 & \\
\hline
\end{tabular}

brightness due to differences among families. The corresponding results for pupae formed in the white cylinders did not reveal a significant among family component. However, the variance in brightness values was greater for the empty cases of pupae formed in the white cylinders ( $F=$ $3 \cdot 24, p<0 \cdot 001)$.

Predation was so severe in the field experiments that no pupae survived to eclosion, and over 80 per cent of the pupae were eliminated in the first 7 weeks of the experiment. The association between crypsis and probability of survival was tested by comparing the survival of cryptic and noncryptic pupae over approximately their first 2 weeks in the field (table 4) and by comparing the rates of elimination of cryptic and noncryptic pupae over approximately the first 7 weeks in the field (table 5). After about 2 weeks in the field, cryptic pupae were out-surviving noncryptic pupae in five of the six experiments, and in one experiment (84C) this difference was significant (table 4). Because the pupae in each experiment were not sampled on precisely the same day, it was not possible to pool the results, even though overall 60 per cent (172 out of 288 ) of the cryptic as opposed to 44 per cent (110 out of 249) of the noncryptic pupae were surviving. However, an overall association between survival and crypsis was tested by combining the six chi square values into a standardized normal deviate (Simpson, Roe and Lewontin, 1960, Ch. 13). This test shows a significant association between crypsis and survival (standardized normal deviate $=3 \cdot 54, p<$ $0.001)$.

Table 5 shows the results of regression analyses of survival for cryptic and noncryptic pupae over approximately the first 7 weeks in the field. The goodness of fit of the data to a constant mortality model was good for all regressions. For five of the six experiments cryptic pupae had higher daily probabilities of survival than noncryptic pupae, but this difference was significant only in experiment $84 \mathrm{~A}$.

\section{DISCUSSION}

The experiments reported here were designed to test three hypotheses. First, that the darkness of brown $P$. polyxenes pupae is a phenotypically plastic trait, environmentally cued by the darkness of the pupation site; second, that the adaptive significance of this plasticity is enhanced crypsis; and third, that adaptation to environmental heterogeneity by phenotypic plasticity is mutually 
Table 4 Survival of cryptic and noncryptic pupae by experiment after approximately two weeks in the field

\begin{tabular}{|c|c|c|c|c|}
\hline Experiment & Pupation site & $\begin{array}{l}\text { No. } \\
\text { pupae }\end{array}$ & $\begin{array}{l}\% \\
\text { alive }\end{array}$ & $\chi^{2}$ \\
\hline \multirow[t]{2}{*}{$82 \mathrm{~A}$} & cryptic & 83 & 43 & $3 \cdot 12$ \\
\hline & noncryptic & 68 & 29 & \\
\hline \multirow[t]{2}{*}{$83 \mathrm{~A}$} & cryptic & 60 & 58 & $2 \cdot 87$ \\
\hline & noncryptic & 67 & 43 & \\
\hline \multirow[t]{2}{*}{$84 \mathrm{~A}$} & cryptic & 51 & 69 & $2 \cdot 98$ \\
\hline & noncryptic & 43 & 51 & \\
\hline \multirow[t]{2}{*}{$84 \mathrm{~B}$} & cryptic & 22 & 95 & $1 \cdot 5$ \\
\hline & noncryptic & 26 & 82 & \\
\hline \multirow[t]{2}{*}{$84 \mathrm{C}$} & cryptic & 53 & 74 & $14 \cdot 0^{*}$ \\
\hline & noncryptic & 29 & 38 & \\
\hline \multirow[t]{2}{*}{$84 \mathrm{D}$} & cryptic & 19 & 16 & $2 \cdot 14$ \\
\hline & noncryptic & 16 & 38 & \\
\hline
\end{tabular}

$*=p<0 \cdot 001$.

Table 5 Results of regression analysis (ln percent pupae surviving on days in field) by experiment, showing estimated daily probabilities of survival $(1-b)$, goodness of fit to constant mortality model $\left(r^{2}\right)$ and significance tests for differences between the survival of cryptic and noncryptic pupae

\begin{tabular}{|c|c|c|c|c|}
\hline Experiment & Pupation site & $1-b$ & $r^{2}$ & Significance \\
\hline \multirow[t]{2}{*}{$82 \mathrm{~A}$} & cryptic & 0.9359 & $98 \cdot 1$ & $0.1<p<0.2$ \\
\hline & noncryptic & 0.9186 & $92 \cdot 8$ & \\
\hline \multirow[t]{2}{*}{$83 \mathrm{~A}$} & cryptic & 0.9737 & $88 \cdot 4$ & $0.05<p<0.1$ \\
\hline & noncryptic & 0.9685 & $90 \cdot 0$ & \\
\hline \multirow[t]{2}{*}{$84 \mathrm{~A}$} & cryptic & 0.9761 & $92 \cdot 3$ & $p<0.05$ \\
\hline & noncryptic & 0.9627 & $94 \cdot 2$ & \\
\hline \multirow[t]{2}{*}{$84 \mathrm{~B}$} & cryptic & $0 \cdot 9840$ & $86 \cdot 0$ & $0.3<p<0.4$ \\
\hline & noncryptic & $0 \cdot 9880$ & $90 \cdot 0$ & \\
\hline \multirow[t]{2}{*}{$84 \mathrm{C}$} & cryptic & 0.9522 & $93 \cdot 6$ & $0.3<p<0.2$ \\
\hline & noncryptic & 0.9433 & $98 \cdot 2$ & \\
\hline \multirow[t]{2}{*}{$84 \mathrm{D}$} & cryptic & 0.9427 & $86 \cdot 1$ & $p<0.5$ \\
\hline & noncryptic & 0.9426 & $95 \cdot 5$ & \\
\hline
\end{tabular}

exclusive of adaptation by genetic variability. The results are consistent with the predictions of the first two hypotheses, but question the general validity of the third.

The first hypothesis is supported by the results of three analyses of the darkness of brown pupae, each showing that brown pupae formed on black construction paper are significantly darker than those formed on white paper. These results support the suggestion of West et al. (1972) that differences in the darkness of brown diapausing $P$. polyxenes pupae are a reflection of differences in the darkness of their pupation sites. In addition, our results show that plasticity in darkness is not limited to diapausing pupae, as the empty pupal cases of non-diapausing pupae also showed a significant association of pupal darkness with the darkness of the pupation site. The influence of pupation site darkness represents an addition to the list of environmental cues, such as larval photoperiod, pupation site colour and pupation site texture, which are already known to affect pupal colour in $P$. polyxenes (West et al., 1972; Smith, 1978; Hazel and West, 1979, 1983; West and Hazel, 1985).

The second hypothesis, that phenotypic plasticity in pupal darkness is adaptive because it allows for the production of cryptic pupae on variable brown pupation sites, predicts that cryptic pupae will have a higher probability of escaping predation than will noncryptic pupae. Overall, the results of our field experiments support this prediction. After approximately 7 weeks in the field, the rates of elimination of noncryptic pupae were 
greater than those of cryptic pupae in 5 out of the 6 experiments. This difference was significant in one experiment and approached formal significance in another. An analysis of survival over approximately the first 2 weeks gave similar results, with cryptic pupae having a higher survival in 5 out of 6 experiments. This difference was also significant in one experiment, and approached formal significance in another. Taken together, these results show a clear overall association between crypsis and survival.

Our estimates of genetic variation in the darkness of brown pupae were different for pupae formed in the black and white cylinders. In the black cylinders, there was a significant genetic component to variation in darkness, while for pupae formed in the white cylinders the genetic component was not significant. We recognise that for the purpose of estimating the genetic components of variation, full sib analysis is the least reliable because of the potential correlation in sibs due to maternal effects and common environment (Falconer, 1981). Yet, these possible causes of resemblance do not explain why the among families components of variation are so different for pupae formed in the two treatments. One explanation for the difference is that it reflects a genotype-environment interaction (Falconer, $1952,1981)$. However, we feel a more likely explanation is that much of the variation in the darkness of pupae formed in the white cylinders was environmental, being due to the presence of adjacent prepupal larvae. Prepupal P. polyxenes larvae are black with alternating green and yellow bands, and when several prepupal larvae are placed in the same pupation cylinder, they often follow each other's silk trails and end up pupating close together. In the black paper cylinders, prepupae were nearly as dark as the black paper, and therefore should not have influenced the darkness of the pupation environment as perceived by adjacent prepupae. However, in the white cylinders, the clumped distribution of dark prepupae could have been a source of environmental variation, causing differences among prepupae in their perception of the darkness of their surroundings. The larger total variance in darkness of pupae formed in the white cylinders is consistent with this explanation.

It has been suggested that phenotypic plasticity and genetical variability are mutually exclusive means of adaptation to environmental heterogeneity (Thoday, 1953; Marshall and Jain, 1968; Jain, 1979). In brown P. polyxenes pupae, variation in darkness is both genetic and environmental. But, it is important to note that genetic variation in darkness could only be detected when the pupation conditions were rigidly controlled, such as when pupation occurred in the black cylinders. When pupation conditions were only slightly variable, as when pupation occurred in white cylinders, environmental variation swamped genetic variation, making it scarcely detectable. Because in nature the darkness of pupation sites is likely to be highly variable, most phenotypic variation in the darkness of brown pupae will be environmental, the result of phenotypic plasticity, making any selection acting on differences in darkness weak at best. Similar arguments have been applied to pupal colour dimorphism. In this case, green and brown pupae are produced in response to cues associated with the colour of the pupation site, but individuals differ genetically in the ease with which they can form the alternative colours. On a given pupation site, differences in pupal colour are mostly genetic, but when pupation sites vary (as they do in nature), most differences in pupal colour are environmental (Hazel, 1977; Hazel and West, 1982; Sims, 1983).

Theoretical models (Via and Lande, 1985) suggest that phenotypic plasticity should be maintained at an optimum level by stabilizing selection. But since, in the absence of a cost, stabilizing selection results in a loss of genetic variation at equilibrium (Scharloo, 1964; Wright, 1969, Ch. 4), any maintenance of genetic variation will be the result of a balance between mutation and selection (Via and Lande, 1985; Lande, 1976, 1980; Turelli, 1984). Phenotypically plastic traits, such as pupal colour, by their very nature should be expected to have low heritabilities under natural conditions. As a result, the efficacy of natural selection in eliminating genetic variation in such traits will be reduced, and a balance between mutation and selection might be more readily obtained. Alternatively, if individuals with the optimum level of plasticity are largely heterozygous, then selection will actively maintain genetic variation (Via and Lande, 1985). In neither case would one expect selection for phenotypic plasticity and the maintenance of genetic variability to be incompatible.

Acknowledgements J. Cunningham and L. Scott assisted in the collection of data. M. D. Johnson and D. A. West provided comments on the manuscript. T. Pigg, E. Snizek, J. Feiroh, P. Hovda and J. Rud ranked the pupae. The reflectance spectrophotomer was provided by D. A. West. Several anonomous reviewers provided helpful comments. Support was provided by the Department of Biological Sciences at DePauw University. We thank them all. 


\section{REFERENCES}

BAKER, H. G. 1965. Characteristics and modes of origin of weeds. In Baker, H. G. and Stebbins, G. L. (eds.) The Genetics of Colonizing Species, Academic Press, N.Y. pp. 147-172.

BRADSHAW, A. D. 1965. Evolutionary significance of phenotypic plasticity in plants. Adv. Genet., 13, 115-155.

CLARKE, C. A. AND SHEPPARD, P. M. 1962. Offspring from double matings in swallowtail butterflies. The Entomologist, August.

ClARKe, C. A. AND SHEPpard, P. M. 1972. Genetic and environmental factors influencing pupal colour in the swallowtail butterflies Battus philenor (L.) and Papilio polytes L. J. Entomol., (A) 46, 123-133.

FALCONER, D. S. 1952. The problem of environment and selection. Am. Natur., 86, 293-298.

FALCONER, D. S. 1981. Introduction to Quantitative Genetics. 2nd ed. Longman, New York.

Gause, G. F. 1947. Problems of evolution. Trans. Conn. Acad. Sci., 37, 17-68.

GotTlieb, L. D. 1977. Phenotypic variation in Stephanomeria exigua ssp. coronaria (Compositae) and its recent derivative species "Malheurensis". Amer. J. Bot., 64, 873-880.

HAZEL, W. N. 1977. The genetic basis of pupal colour dimorphism and its maintenance by natural selection in Papilio polyxenes (Papilionidae: Lepidoptera). Heredity, 38, 227236.

HAZEL, W. N. AND WEST, D. A. 1979. Environmental control of pupal colour in swallowtail butterflies (Lepidoptera: Papilioninae): Battus philenor (L.) and Papilio polyxenes Fabr. Ecological Entomology, 4, 393-400.

HAZEL, W. N. AND WEST, D. A. 1982. Pupal colour dimorphism in swallowtail butterflies as a threshold trait: selection in Eurytides marcellus (Cramer). Heredity, 49, 295-301.

HAZEL, W. N. AND WEST, D. A. 1983. The effect of larval photoperiod on pupal colour and diapause in swallowtail butterflies. Ecological Entomology, 8, 37-42.

JAIN, S. K. 1978. Inheritance of phenotypic plasticity in soft chess, Bromus mollis L. (Gramineae). Experimentia, 34, 835-836.

JAIN, S. K. 1979. Adaptive strategies: polymorphism, plasticity, and homeostasis. In Solbrig, O. T., Jain, S. K., Johnson. G. B. and Raven, P. H. (eds.) Topics in Plant Population Biology, Columbia University Press, New York, pp. 160187.

LANDE, R. 1976. The maintenance of genetic variability by mutation in a polygenic character with linked loci. Genet. Res., 26, 221-235.

LANDE, R. 1980. The genetic covariance between characters maintained by pleiotropic mutations. Genetics, 94, 203-215.

LEVIS, R. 1963. Theory of fitness in a heterogeneous environment. II. Developmental flexibility and niche selection. Amer. Natur., 97, 75-90.
MARShALL, D. M. AND JAIN, S. K. 1968. Phenotypic plasticity of Avena fatua and A. barbata. Am. Natur., 102, 457-467.

SCHARLOO, w. 1964. The effect of disruptive and stabilizing selection on the expression of cubitus interruptus in Drosophila. Genetics, 50, 553-562.

SCHEINER, S. M. AND GOODNIGHT, C. J. 1984. The comparison of phenotypic plasticity and genetic variation in populations of the grass Danthonia spicata. Evolution, 38, 845-855.

SCHLiChTiNG, C. D. AND LEVIN, D. A. 1984. Phenotypic plasticity of annual Phlox: Tests of some hypothesis. Amer. $J$. Bot., 71, 252-260.

SIMPSON, G. G., ROE, A. AND LEWONTIN, R. C. 1960. Quantitative Zoology, Harcourt, Brace and Co., Inc. New York.

SIMS, S. R. 1983. The genetic and environmental basis of pupal colour dimorphism in Papilio zelicaon (Lepidoptera: Papilionidae). Heredity, 50, 159-168.

SMITH, A. G. 1978. Environmental factors influencing pupal colour in Lepidoptera. I. Experiments with Papilio polytes, Papilio demoleus, and Papilio polyxenes. Proceedings of the Royal Society of London, B., 200, 295-329.

Thoday, J. M. 1953. Components of fitness. Symp. Soc. Exptl. Biol, , 7, 96-113.

TURELLI, M. 1984. Heritable genetic variation via mutationselection balance: Lerch's zeta meets the abdominal bristle. Theoret. Popul. Biol., 25, 138-193.

VIA, S. AND LANDE, R. 1985. Genotype-environment interaction and the evolution of phenotypic plasticity. Evolution, 39, 505-522.

WeSt, D. A., SNEllings, W. M. AND herbeK, T. A. 1972. Pupal colour dimorphism and its environmental control in Papilio polyxenes asterius Stoll. (Lepidoptera: Papilionidae). J. N. Y. Entomol. Soc., 80, 205-211.

WEST, D. A. AND HAZEL, W. N. 1979. Natural pupation sites of swallowtail butterflies (Lepidoptera: Papilioninae): Papilio polyxenes Fabr., P. glaucus L. and Battus philenor (L). Ecological Entomology, 4, 387-392.

WeSt, D. A. AND HAZEL, W. N. 1985. Pupal colour dimorphism in swallowtail butterflies: timing of the sensitive period and environmental control. Physiological Entomology, 10, 113-119.

WIKLund, c. 1972. Pupal coloration in Papilio machaon in response to wavelength of light. Naturwissenschaften, 59, 219.

WIKLUND, C. 1975. Pupal colour polymorphism and the survival in the field of cryptic and non-cryptic pupae in Papilio machaon L. J. Roy. Ent. Soc. Lond., 127, 73-84.

WILKEN, D. H. 1977. Local differentiation for phenotypic plasticity in the wild annual Collomia linearis (Polemoniaceae). Syst. Bot., 2, 99-108.

WRIGHT, S. 1969. Evolution and the Genetics of Natural Populations, Vol. 2. The Theory of Gene Frequencies. Univ. of Chicago Press, Chicago, IL. 